\title{
Study of autonomic sympatho-vagal modulation in different trimesters of pregnancy
}

\author{
Kochhar $\mathbf{S}^{1}$, Swaran $\mathbf{J}^{2}$, Ummat $\mathbf{A}^{3}$ \\ ${ }^{1}$ Dr. Sonia Kochhar, Professor, Department of Physiology, Maharishi Markandeshwar Institute of Medical Sciences and \\ Research, Mullana, (Haryana) India, ${ }^{2}$ Dr. Swaran Jit. Associate Professor, Department of Physiology, Govt. Medical \\ College, Amritsar (Punjab) India, ${ }^{3}$ Dr. Ashwani Ummat, Associate Professor, Orthopedic Department, Maharishi \\ Markandeshwar Institute of Medical Sciences and Research, Mullana, (Haryana) India.
}

Address for Correspondence: Dr. Swaran Jit. Associate Professor, Deptt. of Physiology, Govt. Medical College, Amritsar (Punjab) India. E-mail: jswaran09@gmail.com

\begin{abstract}
Introduction: Various physiological conditions are known to influence functional activity of ANS and one such state is pregnancy. Pregnancy is associated with profound but temporary and reversible hemo-dynamic changes in mother to support fetal development and growth but without permanent deleterious effects in the mother. Material \& Methods: Functional status of Autonomic Nervous System during $1^{\text {st }}, 2^{\text {nd }}$ and $3^{\text {rd }}$ trimester of pregnancy was studied in 75 pregnant women in all three trimesters of pregnancy (25 each) and results were compared among them and with another 25 nonpregnant women taken as control. Parasympathetic activity was assessed by Standing to Lying down ratio, 30:15 ratio, Valsalva ratio and Tachycardia ratio. The assessment of sympathetic activity was done by tests viz. CPT, HGT and GSR. Results: Parasympathetic activity was significantly reduced in $3^{\text {rd }}$ trimester of pregnancy in comparison to non-pregnant controls as well as $1^{\text {st }}$ and $2^{\text {nd }}$ trimesters. The sympathetic activity showed significant rise in sympathetic nervous system activity during $3^{\text {rd }}$ trimester of pregnancy in comparison with the changes in non-pregnant controls as well as $1^{\text {st }} \& 2^{\text {nd }}$ trimester of pregnancy. Conclusion: Although ANS play a central role in the adaptation of hemodynamic to various demands of pregnancy yet its failure to achieve the required goal during different trimesters of pregnancy is poorly understood and needs to be investigated. This havoc of sympatho-vagal modulation in pregnancy can be attributed to orthostatic dys-regulation occurring due to deficiency of autonomic nervous control mechanisms in pregnancy and we have tried to prove this in our study.
\end{abstract}

Key words: Pregnancy trimesters, sympatho-vagal modulation, ANS activity, orthostatic hypotension, cardiovascular regulation.

\section{Introduction}

1. Autonomic Stress and normal Pregnancy: Autonomic nervous system controls the vegetative functions of body without our conscious control. Parasympathetic division of ANS governs the functions during rest like gastric emptying and anabolic part of metabolism and sympathetic activation is involved in the preparation of body for stress and physical activity. Both serves to maintain the optimal internal environment of the body and achieves this by mechanisms that regulate blood pressure, fluid and electrolyte balance, and body temperature [1]. ANS is

Manuscript received $5^{\text {th }}$ April 2016

Reviewed: $16^{\text {th }}$ April 2016

Author Corrected: $28^{\text {th }}$ April 2016

Accepted for Publication $14^{\text {th }}$ May 2016 directly involved in tonic, reflex, and adaptive control of autonomic function, and integrates autonomic functions with hormonal, immuno-modulatory and pain controlling mechanisms to internal and external environmental challenges [2]. Various physiological conditions are known to influence functional activity of ANS and one such state is pregnancy. Pregnancy is associated with profound but temporary and reversible hemo-dynamic changes in the mother to accommodate and support fetal development and growth but without permanent deleterious effects in the mother [3]. Increase in the resting heart rate in the pregnant women is explained by increased Bainbridge reflex occurring due to the increase in the end diastolic volume caused 
by hemo-dilution [4]. During pregnancy there is an increase in the blood volume, heart rate and cardiac output while peripheral resistance and resting blood pressure decreases [5].

Endocrinal and neural regulatory mechanisms affecting the cardiovascular system undergo changes even during normal progression of pregnancy. Hypothalamicpituitary-adrenal axis (HPA) reacts to sustained anxiety and depression. Change in physiological hemodynamics during pregnancy may affect uterine circulation, in turn decreasing blood flow reaching the decidua, and thus affecting the implantation site [6]. Increased levels of circulating catecholamines play an adverse role in the emotional centers of the brain which causes an increased steroidogenesis. The endocrinal manifestations of these increased steroid hormones cause volume overload, which ultimately puts stress on the autonomic activity. Suggested factors leading to orthostatic hypotension include impaired vascular innervations, high plasma nor-epinephrine concentrations, decreased $\alpha$-receptor sensitivity, $\beta$-receptor hypersensitivity [7] and other researchers added baro-receptor dysfunction in the above list [8]. Orthostatic deregulation is also known to lead to spontaneous abortion, low birth weight babies and still births.

Although ANS plays a central role in the adaptation of circulation to various demands of pregnancy still its failure to achieve the required goal during different trimesters of pregnancy is poorly understood and needs to be investigated. This carnage can be attributed to the orthostatic dys-regulation occurring due to deficiency of autonomic nervous control mechanism in pregnancy as we have tried to prove this in our study.

2. Autonomic Stress testing: In 1960 a simple finding of absence of circulatory reflexes in diabetic neuritis started an era to diagnose autonomic disorders by using circulatory reflexes. The changes in blood pressure and heart rate due to Valsalva maneuver [9]. The concept for autonomic testing began developing at the turn of the 19th century with a number of experiments done in those days in basic neurophysiology [10].

These original tests were developed over time into a rigorously defined, standardized series of autonomic tests that are useful in the clinical assessment and care of patients with suspected autonomic disorders. Autonomic testing has been widely used in clinical practice for 50 years, with decades of extensive experience and thousands of studies published on its use [11].

Most of the classic cardiovascular reflex tests provide information of the overall integrity of the baroreflex arc. Afferent and central integrity of the baroreflex arc cannot be accessed directly.

The common approach is to evaluate the integrity of the efferent pathways. If these are normal, the disturbance is supposed to be on the afferent or central site of the arterial baroreflex arc. The overall integrity of the baroreflex arc can be assessed by analyzing the heart rate and blood pressure responses to orthostatic posture or Valsalva straining [12]. By placing the hand in ice water or exercise, such as sustained handgrip are selective physiological stressors to test the efferent sympathetic pathways. Selective evaluation of efferent cardiac vagal pathways can be performed by the forced breathing maneuver against the closed glottis [13] [14] [15].

Spectral analysis of the heart period (RR interval) and systolic arterial pressure variability also provide information on the intact sympathetic and parasympathetic pathways and their balance [16].

\section{Material and Methods}

This study was conducted on 100 normal healthy women (75 pregnant \& 25 non-pregnant) in the age group of 20-40 years taken from the OPD and wards of Obstetrics and Gynecology Department of Guru Nanak dev Hospital Amritsar, Amritsar.

Subjects were divided in four groups:

- Group I: 25 non-pregnant women as control group

- Group II: 25 pregnant women in $1^{\text {st }}$ trimester of pregnancy

- Group III: 25 pregnant women in $2^{\text {nd }}$ trimester of pregnancy

- Group IV: 25 pregnant women in $3^{\text {rd }}$ trimester of pregnancy.

None of these women were suffering from any serious illness which could be affecting the functioning of autonomic nervous system viz. Diabetes mellitus, Hypertension or Neuro-psychiatric disorders. A verbal and written consent was taken from each subject and the nature of tests was explained to them. 
Following anthropometric measurements and ANS function tests were done:

1) Anthropometry: Height $(\mathrm{cm})$ and Weight $(\mathrm{kg})$ Pulse, B.P. by Sphygmomanometer

2) ANS Function Tests:

(a) For functional status of Para-sympathetic

Nervous System

1) Standing to Lying down ratio-S/L Ratio

2) $30: 15$ Ratio
3) Valsalva Ratio

4) Tachycardia ratio

All these tests were done on ECG machine.

(b) For functional status of Sympathetic Nervous System:

1) Cold pressor test $-\mathrm{CPT}$

2) Hand Grip test- HGT

3) Galvanic Skin Resistance -GSR

These tests were done on Polyrite Machine

\section{Statistical analysis:}

Table I: Comparative study of parasympathetic function tests in the four groups $(n=100 *)$.

\begin{tabular}{|l|l|l|l|l|}
\hline Parameters & Group I & Group II & Group III & Group IV \\
& Mean \pm SD & Mean \pm SD & Mean \pm SD & Mean \pm SD \\
\hline S/L ratio & $1.19 \pm 0.11$ & $1.23 \pm 0.07$ & $1.21 \pm 0.12$ & $1.03 \pm 0.10$ \\
\hline $30: 15$ ratio & $1.03 \pm 0.07$ & $1.02 \pm 0.07$ & $1.04 \pm 0.06$ & $1.07 \pm 0.04$ \\
\hline Valsalva ratio & $1.62 \pm 0.21$ & $1.66 \pm 0.30$ & $1.53 \pm 0.33$ & $1.46 \pm 0.30$ \\
\hline Tachycardia ratio & $0.82 \pm 0.07$ & $0.81 \pm 0.23$ & $0.82 \pm 0.13$ & $0.76 \pm 0.12$ \\
\hline
\end{tabular}

* 25 in each group $\mathrm{S} / \mathrm{L}$ ratio: Standing to lying down ratio,

Table II: Comparative study of parasympathetic function tests in the four groups $\left(\mathbf{n}=100^{*}\right)$.

\begin{tabular}{|l|l|l|l|l|l|l|}
\hline Parameters & II v/s I & III v/s I & IV v/s I & III v/s II & IV v/s II & IV v/s III \\
\hline S/L ratio & $>0.05$ & $>0.05$ & $<0.001^{* *}$ & $>0.05$ & $<0.001^{* *}$ & $>0.05$ \\
\hline $30: 15$ ratio & $>0.05$ & $>0.05$ & $<0.05^{*}$ & $>0.05$ & $<0.05^{*}$ & $<0.05^{*}$ \\
\hline Valsalva ratio & $>0.05$ & $>0.05$ & $<0.05^{*}$ & $>0.05$ & $<0.05^{*}$ & $>0.05$ \\
\hline Tachycardia ratio & $>0.05$ & $>0.05$ & $<0.05^{*}$ & $>0.05$ & $>0.05$ & $>0.05$ \\
\hline
\end{tabular}

p-Value ( *Significant **Highly Significant).

Table I \& II showing mean value for S/L ratio was highly significant ( $\mathrm{p}<0.001 * *$ ) in the $3^{\text {rd }}$ trimester (group IV) compared to the controls (group I), $1^{\text {st }}$ (group II) $\& 2^{\text {nd }}$ trimester (group III) of pregnancy. mean value of 30:15 ratio showed significant $\left(\mathrm{p}<0.05^{*}\right)$ changes in the $3^{\text {rd }}$ trimester (group IV) compared with controls (group I), the $1^{\text {st }}$ trimester (group II) and $2^{\text {nd }}$ trimester (group III) of pregnancy $(\mathrm{p}<0.05)$.

Mean value of Valsalva ratio showed significant $\left(\mathrm{p}<0.05^{*}\right)$ results in the $3^{\text {rd }}$ trimester (group IV) compared to controls (group I) and the $1^{\text {st }}$ trimester (group II) of pregnancy $(\mathrm{p}<0.05)$. The mean value of Tachycardia ratio also showed significant $\left(\mathrm{p}<0.05^{*}\right)$ variation between $3^{\text {rd }}$ trimester (group IV) and control group I $(\mathrm{p}<0.05)$. From these tests it was concluded that parasympathetic activity decreased in the $3^{\text {rd }}$ trimester of pregnancy. 
Table III: Comparative study of sympathetic function tests in the four groups $(n=100)$.

\begin{tabular}{|c|c|c|c|c|}
\hline Parameters & $\begin{array}{l}\text { Group I } \\
\text { Mean } \pm \text { SD }\end{array}$ & $\begin{array}{l}\text { Group II } \\
\text { Mean } \pm \text { SD }\end{array}$ & $\begin{array}{l}\text { Group III } \\
\text { Mean } \pm \text { SD }\end{array}$ & $\begin{array}{l}\text { Group IV } \\
\text { Mean } \pm \text { SD }\end{array}$ \\
\hline \multicolumn{5}{|l|}{ 1. CPT } \\
\hline $\begin{array}{l}\text { Rise in SBP } \\
(\mathrm{mmHg})\end{array}$ & $14.80 \pm 5.51$ & $14.88 \pm 5.29$ & $15.12 \pm 7.07$ & $18.32 \pm 5.96$ \\
\hline $\begin{array}{l}\text { Rise in DBP } \\
(\mathrm{mmHg})\end{array}$ & $11.44 \pm 5.40$ & $11.84 \pm 7.09$ & $12.64 \pm 6.37$ & $13.44 \pm 6.70$ \\
\hline \multicolumn{5}{|l|}{ 2. HGT } \\
\hline $\begin{array}{l}\text { Rise in SBP } \\
(\mathrm{mmHg})\end{array}$ & $13.28 \pm 6.40$ & $12.56 \pm 4.95$ & $13.76 \pm 7.22$ & $14.48 \pm 7.44$ \\
\hline $\begin{array}{l}\text { Rise in DBP } \\
(\mathrm{mmHg})\end{array}$ & $15.36 \pm 6.47$ & $15.76 \pm 5.06$ & $16.24 \pm 8.23$ & $18.76 \pm 4.28$ \\
\hline $\begin{array}{l}\text { 3. GSR } \\
(\mathrm{K} \mathrm{Ohm})\end{array}$ & $162.04 \pm 7.27$ & $161.08 \pm 8.56$ & $162.08 \pm 9.70$ & $151.00 \pm 8.82$ \\
\hline
\end{tabular}

CPT: Cold Pressure Test; HGT: Hand Grip Test; GSR: Galvanic Skin Resistance; SBP: Systolic Blood Pressure; DBP: Diastolic Blood Pressure

Table IV: Comparitive study of sympathetic function tests in the four groups $(n=100)$.

\begin{tabular}{|c|c|c|c|c|c|c|}
\hline Parameters & II v/s I & III v/s I & IV v/s I & III v/s II & IV v/s II & IV v/s III \\
\hline \multicolumn{7}{|l|}{ 1. CPT } \\
\hline $\begin{array}{l}\text { SBP } \\
(\mathrm{mmHg})\end{array}$ & $>0.05$ & $>0.05$ & $<0.05^{*}$ & $>0.05$ & $<0.05 *$ & $>0.05$ \\
\hline $\begin{array}{l}\text { DBP } \\
(\mathrm{mmHg})\end{array}$ & $>0.05$ & $>0.05$ & $>0.05$ & $>0.05$ & $>0.05$ & $>0.05$ \\
\hline \multicolumn{7}{|l|}{ 2. HGT } \\
\hline $\begin{array}{l}\text { SBP } \\
(\mathrm{mmHg})\end{array}$ & $>0.05$ & $>0.05$ & $>0.05$ & $>0.05$ & $>0.05$ & $>0.05$ \\
\hline $\begin{array}{l}\text { DBP } \\
(\mathrm{mmHg})\end{array}$ & $>0.05$ & $>0.05$ & $<0.05^{*}$ & $>0.05$ & $<0.05^{*}$ & $>0.05$ \\
\hline 3. GSR (K Ohm) & $>0.05$ & $>0.05$ & $<0.05 *$ & $>0.05$ & $<0.05 *$ & $<0.05 *$ \\
\hline
\end{tabular}

p-Value ( $*$ Significant **Highly Significant)

Table III \&IV showing mean value for rise in Systolic B.P. in response to CPT significantly changed $\left(\mathrm{p}<0.05^{*}\right)$ in $3^{\text {rd }}$ trimester $(18.32 \pm 5.96)$ of pregnancy when compared to non-pregnant controls $(14.80 \pm 5.51)$ and $1^{\text {st }}$ trimester $(14.88 \pm 5.29)$ of pregnancy $(\mathrm{p}<0.05 *)$. No significant difference its mean value for rise in systolic B.P. response to Hand Grip Test (HGT) during 3 trimesters of pregnancy compared to each other and to that of non-pregnant controls $\left(\mathrm{p}>0.05^{*}\right)$. While the mean value for rise in mean diastolic value significantly higher $\left(\mathrm{p}<0.05^{*}\right)$ in $3^{\text {rd }}$ trimester $(18.76 \pm 4.28)$ of pregnancy as compared to non-pregnant controls. Galvanic Skin Response (GSR): Its mean value is showing significant decrease in $3^{\text {rd }}$ trimester $(151.00 \pm 8.82)$ of pregnancy as compared to the control $(162.04 \pm 7.27)$ and compared to the $1^{\text {st }}$ trimester $(161.08 \pm 8.56 *)$ and $2^{\text {nd }}$ trimester $(162.08 \pm 9.70)$ of pregnancy $\left(\mathrm{p}<0.05^{*}\right)$ also. 


\section{Discussion}

A number of studies have reported that there are dynamic changes in the internal milieu during, pregnancy which is associated with blunting of cardiovascular responsiveness to physical challenge. A fairly extensive body of research throughout globe has confirmed by doing well known cardiovascular reflex maneuvers, such as attempted forced exhalation against a closed glottis (Valsalva maneuver), changes in electrocardiogram during changes in posture $(\mathrm{S} / \mathrm{L}$ ration, 30:50 ratio) and changes in systolic Blood Pressure during isometric exercise (e.g., hand grip). These studies on autonomic nervous system functions have demonstrated that there is heart rate variability and abnormal catecholamine responses to these challenges during pregnancy $[17,18,19]$.

Present study was conducted in order to have an in depth assessment of changes occurring in functional activity of ANS (both parasympathetic and sympathetic NS) involved in periods of $1^{\text {st }}, 2^{\text {nd }}$ and $3^{\text {rd }}$ trimester of pregnancy and to compare these changes with each other and with those of non-pregnant women. The parasympathetic activity was significantly reduced in $3^{\text {rd }}$ trimester of pregnancy in comparison to non-pregnant controls, $1^{\text {st }}$ and $2^{\text {nd }}$ trimesters as assessed by S/L ratio which was highly significant in the $3^{\text {rd }}$ trimester $(p<0.05)$ [20]. 30:15 ratio [21] also showed significant changes in the $3^{\text {rd }}$ trimester (group IV) compared with controls and $1^{\text {st }}$ and $2^{\text {nd }}$ trimester of pregnancy. Valsalva ratio [22] and Tachycardia ratio [23] showed similar significant variation in $3 \mathrm{rd}$ trimenter. While the responses to various sympathetic tests viz. CPT, HGT and GSR showed a significant rise in sympathetic nervous activity during $3^{\text {rd }}$ trimester of pregnancy in comparison to the changes in non-pregnant controls and $1^{\text {st }} \& 2^{\text {nd }}$ trimester of pregnancy. These findings of CPT HGT and GSR [21, 22, 23] during $3^{\text {rd }}$ trimester of normal pregnancy suggested that an increased sympathetic modulation is associated with an increase in resting peripheral sympathetic neural discharge having vaso-constrictor properties. A previous study by Kuo CD et al indicated that autonomic nervous activity shifted towards a lower sympathetic and higher vagal modulation in the first trimester, and changed towards a higher sympathetic and lower vagal modulation in the third trimester as gestational age increased [24]. The balance between the hemodynamic changes of pregnancy and aorto-caval compression caused by the enlarging gravid uterus may be responsible for the biphasic changes in autonomic nervous activity during pregnancy. Our findings confirmed higher sympathetic and lower parasympathetic modulation of autonomic functions in late pregnancy. In another study [25] researchers demonstrated that sympathovagal balance is shifted progressively from a higher vagal modulation towards a higher sympathetic modulation, and the recumbent position activated vagal activity. It was suggested that increased sympathetic activity in late pregnancy could affect the duration of labor. Our findings on sympathetic tests viz. CPT, HGT and GSR have confirmed such higher sympathetic modulation especially in the third trimester. Our findings also corroborate with the study of rise in heart rate starting between 2-5 weeks and continuing into the $3^{\text {rd }}$ trimester of pregnancy [26]. The basic cause that comes out from our study is the "stress response" to increasing load on circulatory system. Such modulations in autonomic sympathetic activity induced by different physiological stress conditions, e.g. hypoxia, exposure to cold, physical training etc. is already proved by a study [27]. Pregnancy is similar stress condition on body of mother. There is decrease in vagal activity and the activation of sympathetic system occurring at increasing loads on body. When a non pregnant women lie down, the typical response of the autonomic nervous system is sympathetic suppression and vagal stimulation because gravitational stress is unloaded. However, this response is reversed when women in late pregnancy assume a supine position. There is reversal in the autonomic response in late pregnancy [28]. Our finding conclude the same.

So it is concluded that in normal pregnancy a rearrangement of autonomic nervous tone occurs which could be interpreted as a shift towards a higher sympathetic and lower parasympathetic activity during $3^{\text {rd }}$ trimester of pregnancy by the growing uterus and orthostatic dys-regulation occurring due to deficiency of autonomic nervous control mechanism during pregnancy as proved earlier by a study [29].

\section{Conclusions/ summary}

- Our findings corroborate with the study of rise in heart rate starting between 2-5 weeks and continuing into the $3^{\text {rd }}$ trimester of pregnancy cf. Hunter S, Robson SC [26].

- So it is concluded that in normal pregnancy a rearrangement of autonomic nervous tone occurs which could be interpreted as a shift towards a 
higher sympathetic and lower parasympathetic activity during $3^{\text {rd }}$ trimester of pregnancy for which aorto-caval compression by the growing uterus cf. Kuo CD et al [24] and orthostatic dys-regulation occurring due to deficiency of autonomic nervous control mechanism during pregnancy cf. Neeta Bachlaus [29] may be suggested as the main causative factor. A good blend of rest and physical exercise, and recommended postural changes while lying down would save the mother of many ANS modulations.

\section{Acknowledgements}

Author and co-author deeply acknowledge the contribution of Gynecology department of Guru Nanak Dev Hospital, Amritsar for providing pregnant and non pregnant in and out patients for our study.

Funding: Nil, Conflict of interest: None initiated.

Permission from IRB: Yes

\section{References}

1. Low PA. Clinical autonomic disorders: evaluation and management, Second Edition ed. Philadelphia: Lippincott - Raven (1997).

2. Benarroch EE. The Central autonomic network in Clinical Autonomic Disorders 2nd ed. Low P (ed) Lippincott-Raven Publishers, Philadelphia (1997).:1722

3. Thornburg KL, Jacobson SL et al. Hemodynamic changes in pregnancy. Semin Perinatol. 2000 ; Feb; 24(1): 11-4.

4. Neeta Bachlaus Measurement of Baroreflex \& Sympathetic Control of Haemodynamics in Mid Pregnancy by Orthostatic Test, People's Journal of Scientific Research. 2010.3 (1) :1-4

5. Hytten FE, Leitch I. The Physiology of human pregnancy. 2nd Ed. 1971; Blackwell Scientific Publications, Oxford : 69-131.

6. Barnea ER, Tal J.. Stress related reproductive failure, J IVF ET 1991; 8:15-23.

7. Frohlich E D, Dustan H P, Tarazi R C.. Hyperdynamic beta-adrenergic circulatory state- an overview. Arch Intern Med 1970,1261068-1069.1069.
8. Muenter Swift N, Charkoudian N, Dotson R M. et al. Baroreflex control of muscle sympathetic nerve activity in postural orthostatic tachycardia syndrome. Am J Physiol Heart Circ Physiol 2005, 289H1226-H1233.H1233.

9. Bhatia SG, Sainani GS, Nayak NJ, Diwate PG. Valsalva maneuver as a test of autonomic neuropathy in diabetes mellitus. JAPI 1976; 24:89.

10. Mathias CJ, Bannister R. Autonomic Failure., 4 ed. 1999 Oxford: Oxford University Press.

11. Christopher H. Gibbons, MD, et al Autonomic Testing Model Coverage Policy September, American Academy of Neurology 2, 2014; https://www.aan.com.

12. Low PA, Benarroch EE. Clinical autonomic disorders, 3rd ed. 2008; Philadelphia: Lippincott Williams \& Wilkins.

13. Smit AA, Wieling W, Karemaker JM.. Clinical approach to cardiovascular reflex testing. Clin. Sci. (Colch.) 1996; 91 Suppl:108-112.

14. Wieling W, Karemaker JM : C.J.Mathias and Sir Roger Bannister (ed.) Autonomic Failure, A textbook of Clinical Disorders of the Autonomic Nervous System ed. 1999. Oxford: Oxford University Press;, pp. 196210.

15. R.Banister, C.Mathias : Sir Roger Bannister (ed.): (1988). Autonomic Failure; A textbook of Clinical Disorders of the Autonomic Nervous System, 1999; Oxford: Oxford University Press: 289-307.

16. Pagani M, Furlan R, Pizzinelli P, Crivellaro W, Cerutti S, Malliani A: Spectral analysis of R-R and arterial pressure variabilities to assess sympatho-vagal interaction during mental stress in humans. J Hypertens 1989;7 (suppl 6):S14-S15.

17. Barron W, Mujais S, Zinaman M, Bravo E, Lindheimer M. Plasma catecholamine responses to physiologic stimuli in normal human pregnancy. American Journal of Obstetrics and Gynecology.1986;154:80-84.

18. Ekholm E, Piha S, Antila K, Erkkola R. Cardiovascular autonomic reflexes in midpregnancy. British Journal of Obstetrics and Gynaecology. 1993;100:177-182. 
19. Matthews KA, Rodin J. Pregnancy alters blood pressure responses to psychological and physical challenge. Psychophysiology. 1992;29:232-240.

20. Rodrigues EA, Ewing DJ. Immediate heart rate response to lying down: simple test for cardiac parasympathetic damage in diabetics. Br Med J (Clin Res Ed) 1982 Oct 2;285(6346):916-918.

21. Ewing DJ, Clarke BF. Diagnosis and management of diabetic autonomic neuropathy. Br Med J (Clin Res Ed). 1982 Oct 2;285(6346):916-8.

22. Lewin AB . A simple test of Cardiac function based upon the heart rate changes induced by the Valsalva maneuver. Am J Cardiol 1966;18:90-99.

23. Baldwa VS, Ewingg DJ.. Heart rate response to valsalva maneuver, reproducibility in normal and relation to variation in resting heart rate in diabetics. $\mathrm{Br}$. Heart J. 1977; 37: 641-644.

24. Hines EA, Brown GE.. The cold pressor test for measuring the reactibility of blood pressure. Am Heart J. 1936; 11(1): 1-9.

25. Ewing DJ, Irwing JB, Ken F, Wildsmith JAW, Clarke RF. Cardiovascular response to sustained handgrip in normal subjects and in patients with diabetes mellitus- A test of autonomic function. Clin Sci Mol Med. 1974; 46: 295-306.
26. Heard GE. The psychogalvanic response in the study of sympathetic activity. Br J Surg. 1964; 51 (8): 629-631.

27. Kuo CD, Chen GY, Yang MJ, Lo HM, Tsai YS.. Biphasic changes in autonomic nervous activity during pregnancy. Br. J. Anaesth 2000.; 84 (3): 323-329.

28. Matsuo H, Inoue K, Hapsari ED, Kitano K, Shiotani H. Change of autonomic nervous activity during pregnancy and its modulation of labor assessed by spectral heart rate variability analysis. Clin Exp Obstet Gynecol. 2007; 34(2):73-9.

29. Hunter S, Robson SC. Adaptation of the maternal heart in pregnancy. Br.Heart J (1992)..; 68 (6): 540-543.

30. Perini R, Veicsteinas A. Heart rate variability and autonomic activity at rest and during exercise in various physiological conditions. Eur J Appl Physiol 2003 Oct;90 (3-4):317-25. Epub 2003 Sep 12.

31. Vybiral T, Bryg RJ, Maddens ME, Boden WE. Effect of passive upright on sympathetic and parasympathetic components of heart rate variability in normal subjects. American Journal of Cardiology 1989; 63: 1117-20.

32. Neeta Bachlaus Measurement of Baroreflex \& Sympathetic Control of Haemodynamics in Mid Pregnancy by Orthostatic Test, People's Journal of Scientific Research 2010; 3 Vol.3(1) :1-4.

\section{How to cite this article?}

Kochhar S, Swaran J, Ummat A. Study of autonomic sympatho-vagal modulation in different trimesters of pregnancy. Int J Med Res Rev 2016;4(5):751-757.doi: 10.17511/ijmrr.2016.i05.15. 